\title{
Physical properties of Mesozoic sedimentary rocks from the Perth Basin, Western Australia.
}

\author{
C. DELLE PIANE ${ }^{1}$, L. ESTEBAN ${ }^{1}$, N. TIMMS $^{2}$ AND S. RAMESH ISRANI ${ }^{1}$
}

${ }^{1}$ CSIRO Earth Science and Resource Engineering, Kensington WA xxxx, Australia

${ }^{2}$ Department of Applied Geology, Curtin University, WA xxxx, Australia

Running title: Petrophysics of Perth basin sedimentary rocks

The Perth Basin (PB) hosts important aquifers within the Yarragadee Formation and adjacent geological formations with potential for economic exploitation by both geothermal energy and carbon capture and sequestration. Yet $p$ Published studies on the reservoir quality of the sedimentary units of the PB are very few. This study reports some petrophysical and lithological characteristics of the sedimentary units of interest for geothermal and geosequestration scenarios and help interpolation toward non-sampled intervals. A new fluvial dominated lithofacies scheme was developed for the Mesozoic stratigraphy from four wells drilled in the central Perth Basin (Pinjarra-1, Cockburn-1, Gingin-1 and Gingin-2) based on grain size, sorting, sedimentary structures and colour that relate to the environment of deposition. Systematic laboratory measurements of permeability, porosity, and thermal conductivity were conducted on core samples to investigate a variety of lithofacies and depths from these wells. Empirical correlations are established among the different physical properties, indicating very-encouraging relationships for full PB basin interpolation by instancesuch as between porosity and permeability, when the samples are grouped into 'hydraulic units' defined by a 'flow zone indicator' parameter.

The common principal controls on the PB thermal conductivity are the pore space arrangement and mineralogical content, which is -are strongly lithofacies specific. Therefore the lithofacies type could be a good first-order discriminator for describing spatial variations of thermal conductivity and then estimate their flow zone indicator.

Keywords: Perth Basin, petrophysics, porosity, permeability, thermal conductivity, lithofacies, hydraulic units. 


\section{INTRODUCTION}

The north to north-northwest trending Perth Basin (PB) extends about $1300 \mathrm{~km}$ along the southwestern margin of Australia and is part of the East Gondwana rift system. It contains a thick Permian to Cretaceous succession that incorporates an unconformity associated with the break-up of Australia and Greater India in the Early Cretaceous. The post-break-up succession is relatively thin onshore but thickens rapidly offshore and extends to the edge of the continent-ocean boundary.

Exploration for hydrocarbons in the PB began in the late 1940s; oil and gas has been produced from Jurassic sandstones strata within the Cattamarra Coal Measures, within and underlying the Kockatea Shale, from the Upper upper Permian Dongara Sandstone and Wagina Sandstone, and from the towerlower Permian Irwin River Coal Measures.

A preliminary assessment $b$ Based on sparse data available from petroleum exploration wells $\mathrm{s}_{L} \underline{\text { Bestow }}$ (1982) identified low temperature reservoirs $\left(65-85^{\circ} \mathrm{C}\right)$ at depths of $2.0-3.5 \mathrm{~km}$, as having the best economic potential in the PB (Bestow 1982). More recently the PB has been the subject of studies evaluating its potential for direct use of geothermal energy (e.g. Ghori 2008; Reid et al. 2012; Ricard et al. 2012; Timms et al. 2012) and $\mathrm{CO}_{2}$ geosequestration (Varma et al. 2009; Delle Piane et al. 2013; Stalker et al. 2013).

The aboveThese studies are affected by the limited information available in the literaturepublished data on the distribution of permeability and thermal properties distribution-within the sedimentary units. This information is critical for the successful evaluation and management of the geothermal energy and repository potential of the PB.

The aim of this study is to petrophysically characterise the sedimentary formations in four wells drilled along a north-south transect of the central, onshore part of the PB. Laboratory measurements of porosity, permeability and thermal conductivity on core plugs were used to build empirical relationships between different physical properties of the rocks, and correlated with lithofacies so that they can be applied to field studies for whichwhere only wireline log measurements are available.

\section{REGIONAL GEOLOGY AND STRATIGRAPHY}

The Perth Basin contains a Permian to Holocene sedimentary succession overlying Precambrian basement. The basin originated as a rift with significantly variable rifting rates along its axis that gave rise to temporal variations in the rate of deposition along the basin; variable formation thicknesses are reported reflecting local variations in subsidence (Crostella \& Backhouse 2000).

The stratigraphy of the PB is dominated by fluvial to shallow marine siliciclastic facies; for this study we focussed on Triassic to Jurassic units, especially the Lesueur Sandstone, Cattamarra Coal Measures, Cadda Formation and the Yarragadee Formation. The Cretaceous and overlying units are too thin and shallow to be considered for geosequestration or geothermal energy and porositypermeability degradation with depth considerably reduces the potential of underlying units. The stratigraphic boundaries for our wells are taken from Crostella \& Backhouse (2000), while the sedimentology of the units follows the interpretation presented by Timms et al. (2012, 2013)

Among the stratigraphic units analysed in this study two are of particular interest for their potential commercial exploitation: i) the Lesueur Sandstone, a medium to very coarse grained sandstone representing the potential target for $\mathrm{CO}_{2}$ geosequestration project in the southern PB (Varma et al. 
2009; Stalker et al. 2013); and ii) the Yarragadee Formation, a fine to coarse grained, poorly sorted feldspathic sandstone succession representing the potential target for geothermal projects in the PB (Reid et al. 2012; Timms et al. 2012).

\section{CORE COLLECTION AND EXPERIMENTAL METHODS}

This study is based on the analysis of solid plugs cut from cores from the only four exploration wells drilled in the PB with available cored sections. From south to north, these wells were Pinjarra-1, Cockburn-1, Gingin-1, and Gingin-2 (Figure 1). The cores are housed at the Western Australia Core Library facility of the Geological Survey of Western Australia. Samples were chosen to ensure a statistical representation of the measured physical properties, and to capture intra-formation variations. Table 1 summarises the total depth and the formation tops for the four studied wells.

The solid plugs were cut from homogeneous and coherent sections of whole- and half-slabbed core pieces without 'visible' faults and fractures that could influence physical measurements.

\section{Lithofacies classification scheme}

Little core material was taken from each well as, at the time (in the mid to late 1960s), individual cores were typically 1 to $5 \mathrm{~m}$ long and spaced 100 to $150 \mathrm{~m}$ apart. Despite such an incomplete record, the regular length and spacing of the cored intervals provides a statistically unbiased snapshot of the formations. In Pinjarra-1 28 cores (totalling $60 \mathrm{~m}$ ) were cut; in Cockburn-1 26 cores (65 m); in Gingin-1 28 cores (86 m); and in Gingin-2, 8 cores $(97 \mathrm{~m})$; the number of samples analysed from each well is shown in Table 1. Sedimentary logging at approximately 1:1000 on the cores from Pinjarra-1, Cockburn-1, Gingin-1 and Gingin-2 was used to develop a lithofacies scheme (see Timms et al. 2012, 2013 for details); each sample was assigned a lithofacies type according to sedimentary logging.

Each +Lithofacies was recognised basedwere defined on the distinct physical characteristics of the cored sections including grain size, sorting, sedimentary structures and colour. The primary control on these characteristics is the environment of deposition therefore a lithofacies scheme is commonly interpreted in terms of sedimentary environment; a braided fluvial-dominated facies scheme developed by Miall (1996) was adapted in the interpretation of the sedimentary origin of the units from Cockburn-1, Gingin-1, Gingin-2 and Pinjarra-1.

Nine distinct lithofacies were identified:

1. Ai-Gravel to very coarse sandstone, commonly cross bedded, interpreted to represent high energy fluvial channel fill;

2. Aii-Medium to very coarse cross-bedded sandstone with significant grain size variation between beds, interpreted to be migratory barforms in high energy fluvial channels;

3. Aiii - Thickly bedded massive, coarse sandstone, interpreted to be fluidised fluvial barforms;

4. B - Massive, medium sandstone with flaser cross lamination, interpreted to represent moderate energy migrating fluvial barforms;

5. C - Fine to medium cross laminated sandstone, with common organic fragments and flaser-drapes, interpreted to be moderate to low energy stacked migrating ripples;

6. D - pale grey homogenised muddy sandstone with rootlets and thin coals, interpreted to be floodplain paleosols; 
7. E-Muddy, bioturbated sandstone with slumps and dewatering structures, interpreted to be swampy/lagoonal deposits formed under under waterlogged conditions;

8. F-Interbedded silty fine sandstone and siltstone with trough cross lamination, interpreted to be crevasse splays and overbank deposits;

9. G-Muddy laminated silt with plant fragments and thin laminated fine sandstone, interpreted to be swampy/ overbank deposits.

Grain sorting generally decreases from lithofacies A to $G$. Bioturbation in lithofacies $E$ and $G$ comprises simple sand-filled horizontal burrows and the occasional escape burrow. Lithofacies $F$ is highly variable in grain size and can appear heterolithic in places. Rare synaeresis cracks in lithofacies $\mathrm{G}$ indicate subaqueous shrinkage, possibly due to fluctuations in salinity at the sediment-water interface, rather than desiccation.

\section{Porosity and permeability}

Porosity and permeability were measured in the CSIRO Petrophysics laboratory, Perth, on $38 \mathrm{~mm}$ diameter core plugs approximately $50 \mathrm{~mm}$ in length using an automated helium gas PermeameterPorosimeter AP608 from Coretest Systems Inc. Porosity and permeability are routinely measured on dry samples with a precision of 0.1 and $0.9 \%$, respectively. The technique is widely used in core evaluation and returns the equivalent liquid permeability (i.e. Klinkenberg corrected), which can then be readily used to estimate fluid flow behaviour under the assumption of no interaction between fluid phase and solid rock frame.

Porosity and permeability of each of the cores were measured at an arbitrary confining pressure of 13.8 $\mathrm{MPa}$ (i.e. equivalent to an overburden stress at $500 \mathrm{~m}$ deep sandstone).

\section{Hydraulic units}

Estimation of porosity and permeability is essential for the evaluation of fluid flow and recovery/injection rates in a reservoir. Whereas porosity can be estimated from downhole logging tools, permeability is usually estimated from indirect measurements via correlation with known parameters. Simple porosity-permeability correlation can lead to severe miss-estimation of the capacity for fluid transport of rocks; in this study we use an approach illustrated by Amaefule et al. (1993) based on a generalised version of the Kozeny-Carman relation:

$$
\kappa=\frac{1}{F_{s} \tau^{2} S_{V g r}^{2}} \frac{\phi^{3}}{(1-\phi)^{2}}
$$

Where $\kappa$ is permeability (in $\mathrm{mD}$ ); $\phi$ is the fractional porosity; $F_{s}$ is the pore shape factor; $\tau$ is tortuosity; and $S_{V g r}$ is the specific surface area per unit grain volume. The last three variables are generally difficult to quantify limiting the applicability of the above relation, which can be simplified to:

$$
\log R Q I=\log F Z I+\log \varepsilon
$$

where $\varepsilon$ is the void ratio, $R Q I$ is the reservoir quality index, and $F Z I$ is the flow zone indicator (Amaefule et al. 1993; Prasad 2003). Void ratio $(\varepsilon), R Q I$ and $F Z I$ are defined as follows: 


$$
\begin{aligned}
& \varepsilon=\frac{\phi}{(1-\phi)} ; \\
& R Q=0.0314 \sqrt{\frac{\kappa}{\phi}} ; \\
& F Z I=\frac{1}{\sqrt{F_{s}} \tau S_{V g r}} ;
\end{aligned}
$$

In this way all the geometrical parameters related to pore space are grouped into one single variable (FZI) which can be estimated via laboratory measurements of porosity and permeability:

$$
F Z I=\frac{0.0314}{\varepsilon} \sqrt{\frac{\kappa}{\phi}}
$$

The important outcome of this type of analysis is that rocks characterised by similar FZI also show similar flow properties, i.e. they belong to one hydraulic unit (Prasad 2003).

\section{Thermal properties}

Thermal conductivity $(\lambda)$ was measured on the dry and water saturated core plugs using an Optical Thermal Scanner (OTS) (Popov et al. 1999) at The University of Melbourne, Australia. The measurements were collected by scanning the surface of a sample with a focused heat source in combination with an infrared temperature sensor (Popov et al. 1999). In the instrument, the heat source and temperature sensor are a fixed distance apart, and move in the same direction and same speed so that the sensor records the maximum temperature rise along the heating line behind the source. The comparative temperature differential before and after heating on the sample, and on a standard material (i.e. pure quartz), is used to compute thermal conductivity.

Thermal conductivity can be measured with the OTS to an accuracy of $1.5 \%$ within a range of 0.1 to $70 \mathrm{Wm}^{-1} \mathrm{~K}^{-1}$. The maximum depth of investigation using this instrument is about 0.5 to $1 \mathrm{~cm}$ (i.e. 0.5 to $1 \mathrm{~cm}^{3}$ ). Before the analysis each plug was painted in black to avoid heat reflection; thermal conductivity was then measured by scanning the surface parallel to the plug axis first on dry specimens and then after they had been saturated with tap water under vacuum for 24 hours.

\section{RESULTS}

\section{Porosity and permeability}

The values of porosity and permeability are plotted as a function of depth in Figures 2 and 3. A statistical summary of the measurements is provided in Table 2 with results grouped by formation. In the four wells analysed, the Yarragadee Formation has the highest porosity (up to 36\%) as well as the highest mean porosity (16\%). On the other hand the Cattamarra Coal Measures shows the lowest porosities, with mean values around $5 \%$. Overall, the porosity values show a general trend of reduction with depth. However, within each core porosity varies by several percentile points.

Permeability also attains maximum values in the Yarragadee Formation (up to $1400 \mathrm{mD}$ ), as well as showing the highest mean value in the same formation (approximately $45 \mathrm{mD}$ ). A common result for 
all the formations, however, is that permeability values show a weak trend of reduction with depth, and can change by several orders of magnitude within the same stratigraphic formation (Figure 2).

\section{Thermal conductivity}

Thermal conductivity (TC) measured under dry and water saturated conditions on specimens from the four wells is presented as a function of depth in Figure 4 and summarised in Table 3.

$\mathrm{TC}$ ranges from 2.76 to $3.29 \mathrm{Wm}^{-1} \mathrm{~K}^{-1}$ under dry, and from 4.27 to $4.43 \mathrm{Wm}^{-1} \mathrm{~K}^{-1}$ under saturated conditions. Within each well and each sedimentary unit, some variations of thermal conductivity are observed (Figure 4). The Yarragadee Formation clearly records the lowest thermal conductivity across the wells under dry $\left(2.6 \mathrm{Wm}^{-1} \mathrm{~K}^{-1}\right)$ and saturated conditions $\left(4.3 \mathrm{Wm}^{-1} \mathrm{~K}^{-1}\right)$.

\section{DISCUSSION}

Porosity-permeability relationships for different lithofacies have been derived for the complete data set and reported in Timms et al. $(2012,2013)$, who shows that exponential trend lines fit the data with good correlation in some lithofacies specific grouping, but the statistical correlation dramatically reduces for facies $E, F$ and $G$. The lower statistical correlation could be explained by the small grain sizes, high initial clay content, and lithological variability inherent to these lithofacies.

Here we present an alternative attempt to derive correlations between different physical properties measured on the same rock samples.

\section{Porosity-permeability relationship: hydraulic units grouping}

In situ rock permeability is an elusive parameter and difficult to determine using sub-surface logging technology. Nuclear magnetic resonance (NMR) is currently the technique of choice for permeability estimation using wireline logs, but this logging method post-dates the drilling of the studied wells. Therefore, in situ permeability has to be determined from other commonly acquired parameters,

calibrated to the core data. Using the hydraulic units classification described in section 3.3above it is possible to obtain a framework to relate porosity and permeability according to the $F Z I$ number determined for each tested specimen.

The histogram of the distribution of $F Z I$ values calculated from our dataset (Figure $5 a$ ) shows a multimodal distribution of $F Z I$ ranging from 0.028 to 223 . Samples with similar values of $F Z I$ were grouped into four clusters: 0.01 to $1 ; 1$ to $3 ; 3$ to 10 ; and finally 10 to 250 . This grouping yields very good regression values in terms of relationships between porosity and permeability, as can be seen in Figure $5 \mathrm{~b}$ where a simple power law fitting shows regression coefficients between 0.66 and 1 (Table 4). It should be noted the regression coefficient of 1 for the $F Z I$ class $10-250$ is a function of the small sample population size. Figure $5 \mathrm{~b}$ also shows that samples with similar porosity record a positive correlation between their $F Z I$ class and their permeability, therefore a higher $F Z I$ indicates a comparatively higher permeability.

To check how the lithofacies scheme compares with the hydraulic units grouping ${ }_{\iota}$ ef the same samples population a comparison is made between what is essentially a classification of the depositional environment of the rock samples based on qualitative estimates of grain size and sorting ${ }_{2}$ and characteristic sedimentary structures determined from sedimentary logging and a quantitative characterisation of their measured flow properties. 
No general trend is found when sample assigned to the same lithofacies type are plotted in a depthFZI space (Figure 6).

The samples assigned to each of the 9 lithofacies are plotted as box and whisker graphs against the lithofacies type (Figure 7) indicating that:

- Facies $\mathrm{Ai}$ is characterised by relatively compact spread of $F Z I$, mostly between 3 and 10;

- Facies Aii, and B show very similar distributions and largely fall in the 1-3 FZI grouping, indicating a first order hydraulic likeness;

- Facies Aiii and C show very similar distributions and largely fall in the 0.01 to $1 \mathrm{FZl}$ grouping, indicating a first order hydraulic likeness;

- Facies $D$ is characterised by the lowest $F Z I$ values with the entire population falling within the 0.01 to 1 grouping;

- Facies $\mathrm{E}, \mathrm{F}$ and $\mathrm{G}$ show a wide spread of $F Z I$ values and span two or three classes.

A first order correlation is therefore apparent between lithofacies types and FZI grouping with the former defining distinct subgroups that otherwise show similar hydraulic characteristics.

Permeability predictions for the uncored sections of the wells could-can be performed based on the hydraulic unit profiling performed on each well, for example, by computing probabilities of distribution of each hydraulic unit with depth from the distribution observed on the cores.

Using the cored sections as control intervals for the creation of a reference matrix between different rock properties it would then be possible to establish the probability of having the same hydraulic unit in a given prediction window (Amaefule et al. 1993).

\section{Thermal conductivity considerations}

No satisfactory correlation was found between TC and the other rock physical properties measured in this study. Although $\mathrm{FZI}$ seems a good first order discriminator for porosity and permeability, it does not encompass enough information to be a valid discriminator for thermal conductivity. This could be a consequence of thermal conductivity being strongly dependent on mineralogy (Clauser \& Huenges 1995; Clauser 2006; Tong et al. 2009). Several authors have used this dependency to calculate thermal conductivity from the proportions and thermal conductivity of the dominant mineral phases and neglect the influence of subordinate minerals (McKenna et al. 1996; Ozkahraman et al. 20052004; Abdulagatova et al. 2009). Quartz is the dominant mineral phase in our samples and the proportion of secondary minerals is somewhat lithofacies dependant (Timms et al. 2012).

Given that the depositional environment exerts primary control on the physical characteristics defining a lithofacies, the dependency of thermal conductivity on lithofacies type is mostly controlled by the depositional energy such that high-energy facies (i.e. quartz dominated) show the highest TC, and low energy facies (i.e. flay-clay-rich mudstones) have lower TC values (Figure 8). The presence of water in the pore volume seems to-enhances this trend (Figure 8).

\section{Petrophysical facies signature}

A cross plot of thermal conductivity and $F Z I$ summarises the experimental measurements conducted on the PB sample grouped according to the lithofacies scheme of Timms et al. (2012-_L(Figure 9). The 
plot highlights how different facies may show similar hydraulic properties (e.g. facies B and Aii; and C and Aiii) but can be distinguished based on their thermal conductivity. Therefore by knowing the facies type and the thermal conductivity one can associate a minimum and maximum bound of expected $F Z$. Such an observation may be extrapolated to areas of a basin with similar depositional settings if that the depositional setting is equivalent to the one studied here. Moreover, the relationships between facies type, thermal conductivity and $F Z I$ can potentially be used in areas where core material is not available but facies types can be identified; for example, using wireline logging tools and/or cuttings from drilling operations.

\section{CONCLUSIONS}

This study presents a comprehensive set of petrophysical analysis on core samples from the central Perth Basin. The selected plugs are representative of sedimentary units of fluvial origin presently considered as possible targets for geothermal and $\mathrm{CO}_{2}$ sequestration projects in Western Australia. Despite their important industrial implications, data on the petrophysical properties of such units are critically absent in the open literature, and therefore the new results should provide much needed support for the above-mentioned projects.

The experimental results are interpreted in light of the geology of the central Perth Basin and can be summarised as follows:

1. Measurements of petrophysical properties of samples from nine lithofacies can be grouped into four hydraulically meaningful categories. This analysis shows that stratigraphic boundaries do not account for the intra-formational variation of petrophysical properties in the Perth Basin, but there is a good to excellent relationship between porosity and permeability in samples grouped according to the FZI.

2. An appraisal of the qualitative (lithofacies scheme) and the quantitative (hydraulic units) sample classification indicate a first order correlation between lithofacies types and FZI groups.

3. Thermal conductivity does not follow the same trend and only seems to be related to facies type based on a qualitative description of the mineralogical content and grain arrangement within the rock.

4. In the absence of core or suitable wireline log, a combination of lithofacies type and thermal conductivity may be used to estimate $F Z I$, thereby providing important information on hydraulic properties.

\section{ACKNOWLEDGEMENTS}

The research was supported by CSIRO internal funding scheme to CDP and LE, and by Western Australia Geothermal Centre of Excellence (WAGCoE). We thank the Geological Survey of Western Australia for granting the access to the Core Library Facility, and for the core plug preparation. We are grateful to Sandra Mclarens and the School of Earth from the University of Melbourne to let us access the Optical Thermal Scanner. We thank Cody Evans and Lucas Pimienta (CSIRO internship students) for the thermal conductivity measurements. Arthur Mory and an anonymous reviewer are thanked for their efforts in improving the quality of the manuscript. 


\section{REFERENCES}

Abdulagatova Z., Abdulagatov I. \& Emirov V. 2009. Effect of temperature and pressure on the thermal conductivity of sandstone. International Journal of Rock Mechanics and Mining Sciences 46, 1055-1071.

Amaefule J. O, Altunbay M., Tiab D., Kersey D. G. \& Keelan D. K. 1993. Enhanced Reservoir Description: Using core and log data to identify Hydraulic (Flow) Units and predict permeability in uncored intervals/wells. SPE 26436, presented at $68^{\text {th }}$ Annual Technical Conference and Exhibition, Houston, Texas.

BESTOW T. T. 1982. The potential for geothermal energy, development in Western Australia. Geological Survey of Western Australia Record 1982/6, $67 \mathrm{pp}$.

ClAUSER C. 2006. Geothermal Energy. In: K. Heinloth ed. Landolt-Börnstein, Group VIII: Advanced Materials and Technologies, Vol. 3 Energy Technologies, Subvol. C: Renewable Energies, pp. 480-595. Springer, Heidelberg-Berlin

Clauser C. \& Huenges E. 1995. Thermal conductivity of rocks and minerals. In: Ahrens T. J. ed. Rock Physics and Phase Relations: A Handbook of Physical Constants 3, pp. 105-126. American Geophysical Union, Washington, D.C

Crostella A. \& BACKhouse J. 2000. Geology and Petroleum exploration of the Central and Southern Perth Basin, Western Australia. Geological Survey of Western Australia Report 57.

Delle Piane C., Olierook H. K. H., Timms N. E., Saeedi A., Esteban L., Razaee R., Mikhaltsevitch V. \& LEBEDEV M. 2013. Facies-based rock properties distribution along the Harvey 1 stratigraphic well. CSIRO Report Number EP133710.

GHORI K. A. R. 2008. Perth Basins's geothermal resources. Australian Geothermal Energy Conference 2008.

Gradstein F. M., OGg J. G., Schmitz M. \& OGg G. eds. 2012. The Geologic Time Scale 2012, 2Volume Set (Vol. 2). Elsevier.

MCKenNA T., SHARP JR. J. \& LYNCH F. 1996. Thermal conductivity of Wilcox and Frio sandstones in South Texas (Gulf of Mexico Basin). AAPG Bulletin-American Association of Petroleum Geologists 80, 1203.

Miall A. D. 1992. Alluvial deposits. In: Walker R. G. \& James N. P. eds. Facies models: response to sea level change, pp. 119-142. Geological Association of Canada, Ontario.

MIALL A. D. 1996. The geology of fluvial deposits: sedimentary facies, basin analysis, and petroleum geology. Springer, New York.

Ozkahraman H., SelVer R. \& IsIK E. 2004. Determination of the thermal conductivity of rock from P-wave velocity. International Journal of Rock Mechanics and Mining Sciences 41, 703-708.

Playford P. E., Cockbain A. E. \& Low G. H. 1976. Geology of the Perth Basin, Western Australia. Geological Survey of Western Australia Bulletin 124, $310 \mathrm{p}$.

PRASAD M. 2003. Velocity-permeability relations within hydraulic units. Geophysics 68, 108117.

Popov Y., PribnOW D., SASS J., Williams C. \& BURKhaRdT H. 1999. Characterization of rock thermal conductivity by high-resolution optical scanning. Geothermics 28, 253-276. 
Reid L. B., Corbel S., Poulet T., Ricard L. P., Schilling O., Sheldon H. A. \& Wellman J. F. 2012. Hydrothermal modelling in the Perth Basin, Western Australia. Final report of Project 3, Perth Basin Assessments Program, WAGCoE Report EP121504, April 2012, 202 pp.

Ricard L. P., Trefry M. G., Reid L. B., Corbel S., Esteban L., Chanu J.-B., Wilkes P. G., Douglas G. B., Kaksonen A. H., Lester D. R., Metcalfe G. P., Pimienta L., Gutbrodt S., Tressler S., Bloomfield G., Evans C. \& Regenauer-Lieb K. 2012. Productivity and sustainability of lowtemperature geothermal resources. Final report of Project 4, Perth Basin Assessments Program, WAGCoE Report EP122629, April 2012, 158 pp.

Stalker L., Varma S., VAn Gent D., Haworth J. \& Sharma S. 2013. South West Hub: a carbon capture and storage project. Australian Journal of Earth Sciences 60, 45-58.

Song. T. \& CAwood P. A. 2000. Structural styles in the Perth Basin associated with the Mesozoic break-up of Greater India and Australia. Tectonophysics 317, 55-72.

Timms N. E., Corbel C., Olierook H., Wilkes P. G., Delle Piane C., Sheldon H. A., Alix R., Horowitz F. G., Wilson M. E. J., Evans K. A., Griffiths C., Stütenbecker L., Israni S., Hamilton P. J., Esteban L., Cope P., Evans C., Pimienta L., Dyt C., Huang X., Hopkins J. \& Champion D. 2012. Perth Basin Assessments Program, Project 2: Geomodel. Western Australia Geothermal Centre of Excellence. WAGCoE Report EP122443, April 2012, 202 pp. ISBN: 978-0-643-10905-6.

Timms N. E., Olierook H. K. H., Wilson M. E. J., Delle Piane C., Hamilton P. J., Cope P. \& STÜTENBECKER L. 2013. Sedimentary facies analysis, mineralogy and diagenesis of the Mesozoic aquifers of the central Perth Basin. Submitted to-Marine and Petroleum Geology (submitted)

TONG F., JING L. \& ZIMMERMAN R. 2009. An effective thermal conductivity model of geological porous media for coupled thermo-hydro-mechanical systems with multiphase flow. International Journal of Rock Mechanics and Mining Sciences 46, 1358-1369.

VARMA S., Underschultz J., DANCE T., LANGFord R., Esterle J., Dodds K. \& VAN Gent D. 2009. Regional study on potential $\mathrm{CO}_{2}$ geosequestration in the Collie Basin and Southern Perth Basin of Western Australia. Marine and Petroleum Geology 26, 1255-1273.

WiLKes P. G., TIMMS N. E., HoROWITZ F. G. \& CORBEL S. 2011. A new structural interpretation of the Perth Basin and the Perth metropolitan area using gravity and aeromagnetic data, geomorphology and geology. WA Geothermal Centre of Excellence Report EP117411, Perth, $60 \mathrm{p}$.

Received; accepted

\section{FIGURE CAPTIONS}

Figure 1 (A)Geological map of the central Perth Basin showing the location of the studied wells (modified after Timms et al. 2012); geological timescale, after Gradstein et al. (2012).

Figure 2 Experimentally measured porosity as a function of depth for core plugs extracted from four wells in the Perth Basin. Values of porosity reported in the Figure are those measured at a confining pressure of $13.8 \mathrm{MPa}$.

Comment [AA4]: This can only be

included if it is in press at the time of publication of this paper - is this possible? 
Figure 3 Experimentally measured gas permeability as a function of depth for core plugs extracted from four wells in the Perth Basin.

Figure 4 Experimentally measured thermal conductivity $(\lambda)$ as a function of depth for core plugs extracted from four wells in the Perth Basin.

Figure 5 a) Histogram of the flow zone indicator (FZI) values in the Perth Basin as estimated from a population of 158 . Four families of samples have been discriminated based on the histogram distribution. b) porosity-permeability cross plot for samples grouped according to their $\mathrm{FZI}$ values. Thick lines are the power law fit to the data, regression coefficient of each fit line is reported as $R^{2}$ value, dashed lines are the $95 \%$ confidence bands of each regression.

Figure 6 Relationships between depth, $F Z I$ and lithofacies type for the sample collection analysed in this study.

Figure 7 Comparison between FZI grouping and lithofacies scheme classification of the samples presented in this study. Horizontal dashed lines mark the limit of each FZI group; lower right corner of the figure indicates the statistical values of reported for each population box.

Figure 8 Experimentally measured thermal conductivity as a function of lithofacies typically encountered in the sedimentary units of the Perth Basin.

Figure 9 Comparison between values of $F Z I$ and experimentally measured thermal conductivity (saturated conditions) per facies.

\section{TABLES}

Table 1 Formation tops (in $\mathrm{m}$ ) of the wells used in this study (Crostella \& Backhouse 2000). Ldv = Leederville Formation; SPS = South Perth shale; Jer = Jervoise Sandstone; Oto = Otorowiri Formation; Yarra = Yarragadee Formation; Cadda = Cadda Formation; $\mathrm{CCM}=$ Cattamarra Coal Measures; Ene $=$ Eneabba Formation; Les $=$ Lesueur Sandstone. T.D. = total depth.

Table 2 Statistical values of porosity $(\phi)$ and permeability $(\kappa)$ as measured on core plugs. Values grouped by formation.

Table 3 Descriptive statistics of thermal conductivity $(\lambda)$ as measured on core plugs.

Table 4 Summary of empirical relationships between permeability, porosity, and compressional wave velocity for sample grouped in four $\mathrm{FZI}$ clusters. 